\title{
LAS REPRESENTACIONES GRÉFICAS EN LA FORMACIÓN DE ALUMNOS DE LA CARRERA DE ARQUITECTURA DE LA FAU-UNNE. ARQUITECTURA IU-UPC
}

BIANCHI, Alejandra S. / NILL, Ricardo / TRIPALDI, Gustavo / MERINO, Mario / PINTOS, Gladis / ITURRIAGA, José / VARGAS, Sergio.

gustavotripaldi@hotmail.com--arquimega_2@yahoo.com.ar--abianchipianetti@yahoo.com.ar

Cátedras participantes en el Proyecto de investigación Código 12C006-2013-16. Res. N. 960/12: Sistemas de Representación. Morfología 1. Arquitectura IV. Trabajo Final de carrera. FAU-UNNE.

Palabras Clave: Representación gráfica, diseño, taller virtual.

Keywords: Graphical representation, design, virtual workshop.

\section{RESUMEN}

El objetivo del presente trabajo es exponer los resultados preliminares del proyecto de investigación que estamos desarrollando, para conocer la manera en que los alumnos de arquitectura de nuestra universidad representan el objeto arquitectónico con métodos analógicos y digitales en la actualidad. Se busca contribuir a reformular y producir nuevas estrategias pedagógicas en el proceso de formación en representación para el diseño arquitectónico en la carrera de Arquitectura. Los resultados permiten conocer las habilidades y destrezas del estudiante en relación con los Sistemas de Representación a través de cortes transversales en cinco momentos de la cursada de la carrera durante los ciclos lectivos 2013 a 2016. Fundamentalmente nos explayamos en el Taller Virtual Red Norte Grande, experiencia innovadora y única del taller en Arquitectura IV UPC.

\begin{abstract}
The aim of the present work is to expose the preliminary results of the research project that we are developing, to know how students represent the architectural object with analogical and digital methods nowadays. It seeks to help to reformulate and produce new pedagogic strategies in the process of formation for the architectural design representation in the career of Architecture. The results allow knowing the skills and abilities of the student in relation with representation systems through transverse courts in five moments in the career during the school cycle 2013-2016. Fundamentally, we spread in the "TaIler Virtual Red Norte Grande", the innovative and unique experience in the subject "Arquitectura IV. UPC".
\end{abstract}




\section{OBJETIVO GENERAL}

Contribuir a reformular y producir nuevas estrategias pedagógicas en el proceso de enseñanza de la representación en el diseño arquitectónico, para lograr aprendizajes significativos en los alumnos, durante su formación en la carrera de Arquitectura de la UNNE.

\section{OBJETIVOS PARTICULARES}

- Identificar y conocer las distintas maneras en que los alumnos prefiguran y construyen sus imágenes arquitectónicas.

- Verificar y sistematizar los modos y las herramientas con que los alumnos configuran las imágenes arquitectónicas, a través de un seguimiento pormenorizado de grupos de alumnos en distintos niveles de la carrera de Arquitectura.

\section{INTRODUCCIÓN}

La representación gráfica es la herramienta más poderosa que tiene el arquitecto para configurar el proyecto arquitectónico. En la actualidad, ante la inmediatez de los resultados y gracias a las nuevas tecnologías, han cambiado sustancialmente los sistemas de representación arquitectónica.

La enseñanza de Arquitectura se encuentra en constante actualización frente a los desafíos de la realidad actual y la virtualidad del siglo XXI. Los alumnos realizan la construcción de sus conocimientos en diseño arquitectónico estructurando sus esquemas mediante conocimientos, actitudes, y utilizando herramientas para el diseño en un mundo digital. Se apunta a lograr la integración entre los recursos digitales y tradicionales en un uso conjunto, enfatizando aquello que resulta más positivo en la representación según la etapa de formación del alumno. Como expresa FRANCISCO MARTÍNEZ MINDEGUÍA, "Representar con eficacia, en medio de la explosión de recursos que brindan los sistemas informáticos, exige un constante ejercicio de rigor y selección consciente e intencionada. Algo que requiere gran claridad conceptual. Los sistemas lingüísticos y los sistemas de representación han cambiado rotundamente $y$ en muy poco tiempo... Y, lógicamente, la profesión del arquitecto no ha tenido capacidad ni tiempo material para asimilar ese cambio. Hoy, el ámbito de la representación arquitectónica profesional es un terreno de confusión...".1

La realidad y la virtualidad del siglo XXI nos presentan a la nueva generación de estudiantes del tercer milenio en un nuevo contexto social: un nativo digital que maneja mucha más información de manera diferente, que prefiere gráficos antes que texto, que desea satisfacción inmediata, que quiere personalizar todo, que disfruta compartir emociones, que prefiere más lo divertido que lo funcional, que disfruta de la innovación y que elige jugar de modo serio antes que trabajar. Los mismos docentes frente a un alumno diferente. Es el gran desafío que debemos enfrentar en todos los ámbitos educativos y sociales, no solo en la enseñanza de Sistemas de Representación, sino como actores de la sociedad del siglo XXI: dar criterios y pautas desde nuestras propias prácticas pedagógicas para enfrentarse con mirada crítica a la representación gráfica que debe utilizar el profesional actual.

En el recorrido de formación del arquitecto en la Facultad de Arquitectura de la Universidad Nacional del Nordeste, el alumno desarrolla competencias, conocimientos y habilidades en el dominio de un lenguaje gráfico-expresivo que permite la comunicación integral de todas las etapas del proceso de diseño y su concreción, mediante la utilización idónea de las técnicas e instrumentos de representación. El campo instrumental que le es propio al arquitecto no se entiende como herramienta neutral o pasiva, sino como

1 http://mindeguia.com/congresos/3IAU_M5_13.pdf. 
"Los mismos docentes frente a un alumno diferente. Es el gran desafío que debemos enfrentar en todos los ámbitos educativos y sociales"

elemento fundamental en la formación de la específica visión del profesional. De esta manera, opera sobre la materia misma del diseño, sobre la base de conceptos generalizadores, y no es un componente más, sino un factor integrador de los elementos constituyentes del aprendizaje de la Arquitectura.

\section{DESARROLLO}

La tarea de investigación se encuentra enmarcada en el Proyecto Acreditado por la Secretaría General de Ciencia y Técnica de la UNNE "Las representaciones gráficas en la formación de alumnos de la carrera de Arquitectura de la FAU- UNNE". Resolución N. ${ }^{\circ}$ 960/12 del 28/11/12. Código: 12C006- período 2013-2016. Involucra a docentes de $1 .^{\circ}, 2^{\circ} 4 .^{\circ}$ y $6 .^{\circ}$ año de la carrera, y propone la investigación descriptiva-explicativa sobre las maneras en que los alumnos de Arquitectura de la FAU-UNNE representan las imágenes arquitectónicas con métodos analógicos y digitales en la actualidad. El equipo encaró la temática desde diversas perspectivas, pero con el denominador común de mejorar la calidad del proceso de enseñanza-aprendizaje en la facultad de Arquitectura.

El proyecto propone la investigación descriptiva-explicativa sobre las maneras en que los alumnos de arquitectura de la FAU-UNNE representan las imágenes arquitectónicas con métodos analógicos y digitales en la actualidad. Para ello, se está realizando una evaluación diagnóstica con cortes transversales en cinco momentos de la cursada de la carrera (nivel ingresantes, primero, segundo, cuarto y sexto años), a fin de contribuir a la producción de nuevas estrategias pedagógicas en el proceso de formación y ajustar la planificación de las cátedras y áreas involucradas.

Para el diagnóstico utilizamos un seguimiento fotográfico-digital y un análisis de documentación de croquis, plantas, cortes, vistas, perspectivas polares, axonometrías y maquetas, realizado con medios ana- lógicos y digitales, en dos y tres dimensiones. La información recogida fue procesada conforme a variables tales como conocimientos conceptuales, grado de síntesis, capacidad de comprender y comunicar a través de la gráfica, manejo de las proporciones y destreza para la representación en sus diferentes variantes, manejo de herramientas digitales para expresar ideas durante el proceso de diseño y específicamente en $\mathrm{Ar}$ quitectura IV y el uso de la tecnología que posibilita la interacción en una red virtual. Con los resultados obtenidos, se realizará una propuesta de innovaciones a nivel curricular, que será compartida y difundida a los diferentes actores que intervienen en el proceso de formación de los estudiantes de arquitectura.

El marco teórico de esta investigación para la acción se basa en la teoría de LAWRENCE STENHOUSE, para quien teoría y práctica deben aparecer unidas, y " ... los profesores tienen un papel activo en la investigación de la enseñanza. Mejor que hacer efectivas las ideas de investigadores externos, que sea el profesor el que investigue su propia práctica y valore su situación de una manera crítica. Haciendo esto logrará un desarrollo profesional significativo, se hará más autónomo en los juicios sobre su práctica y descubrirá cómo puede hacer más educativa la enseñanza" .2

Desde la siguiente hipótesis: "La autoevaluación de nuestras propias prácticas docentes arrojará los insumos necesarios para la optimización del proceso de enseñanza- aprendizaje de la representación de la imagen arquitectónica en el proceso de diseño, en los alumnos de la carrera de Arquitectura de la UNNE", el proyecto plantea una metodología de tipo descriptiva-explicativa, basada en la aplicación de pruebas diagnósticas de seguimiento a fin de evaluar al estudiante de Arquitectura en cinco momentos de la carrera (ingresantes, primero, segundo, cuarto y sexto año). Se toma como universo de estudio al conjunto de alumnos estudiantes de Arquitectura de la FAU-UNNE, desde las Áreas de Representación y

2 La investigación como base de la enseñanza. LAWRENCE STENHOUSE. 
de Diseño. La unidad de análisis es cada alumno de ese universo, y el objeto de estudio, la representación sensible y normalizada para el diseño del alumno de Arquitectura de la FAU-UNNE en la actualidad.

La información obtenida debió responder a las diferentes variables, ya mencionadas, tales como conocimientos conceptuales, grado de síntesis, capacidad de comprender y comunicar a través de la gráfica, manejo de proporciones y destreza para la representación, manejo de herramientas digitales para expresar ideas durante el proceso de diseño.

Se analizaron además variables relacionadas con saberes previos de geometría del espacio y con la capacidad para reconocer las tres dimensiones; el nivel de comprensión de consignas; el grado de destreza para el dibujo sensible a mano alzada; el nivel de lenguajes gráficos, plásticos y visuales que poseen según las necesidades de expresión; los niveles de respuesta a la valoración del dibujo como un lenguaje que amplía la capacidad comunicativa; el manejo de los instrumentos en la elaboración de los trabajos; la capacidad para diferenciar la variedad de procedimientos que existen para realizar composiciones en dos y tres dimensiones; la capacidad para reconocer y aplicar la sensación de profundidad en las obras bidimensionales; la capacidad para identificar en una imagen las zonas iluminadas y las sombras; los criterios utilizados para la elección de la tecnología y métodos apropiados a cada una de las distintas fases de un proyecto; la capacidad para utilizar el color en el diseño con criterios fundados; la capacidad para comprender las formas y la expresión de los elementos gráficos; la capacidad para utilizar con corrección y precisión los instrumentos de dibujo técnico; la capacidad para manejar escalas y acotaciones; la capacidad para describir formas y espacios mediante diferentes sistemas de representación y la capacidad para utilizar la terminología adecuada en la identificación y descripción de las imágenes arquitectónicas. Además, se pretende que por medio de las evaluaciones diagnósticas en cinco momentos de la carrera, se profundice en los interrogantes específicos para cada cohorte:

\section{A nivel de ingresantes}

a) conocimientos previos de geometría básica;

b) conocimientos previos de lectura, comprensión y capacidad de respuesta a consignas simples de resolución de ejercicios de dibujo;

c) conocimientos previos de informática y gráfica digital.

\section{A nivel de fines de primer año}

a) avances verificados en relación con los tres puntos evaluados en el ingreso;

b) nivel de destreza para resolver una representación arquitectónica por medios analógicos (en dos y tres dimensiones) en los diferentes sistemas de proyecciones.

c) nivel de destreza para representar una obra de arquitectura a mano alzada (croquis);

d) nivel de destreza para representar una obra de arquitectura con la computadora.

\section{A nivel de segundo año}

- Conocer las distintas maneras en que los alumnos construyen sus imágenes arquitectónicas.

- Verificar si se producen, a partir de croquis gestuales preliminares o croquis posteriores más elaborados, la utilización de maquetas tridimensionales y la representación normalizada final u otras más relacionadas con el campo virtual e informático.

- Identificar las formas en que los alumnos prefiguran sus imágenes.

- Incorporar estrategias innovadoras para el mejoramiento substancial de resultados en los alumnos.

\section{A nivel de cuarto año}

Se procederá a la verificación de los siguientes interrogantes:

- ¿Cuál es el impacto del mundo digital en la enseñanza-aprendizaje del proceso de diseño arquitectónico? - Fundamentalmente, ¿cómo influye en la representación de las ideas arquitectónicas en cada etapa? 
"Los resultados buscan determinar no solo las interrelaciones de los conocimientos entre las asignaturas, sino el estado en que se encuentran los alumnos en cada instancia de evaluación, así como los cambios que experimentan las variables en el transcurso del tiempo."

- La oportunidad de trabajar en una experiencia tal como el Taller Virtual ¿favorece y optimiza la manera de representar las propuestas arquitectónicas?

- ¿El trabajo en red y colaborativo mejora la manera en que los alumnos expresan sus ideas en cada etapa del diseño?

- ¿Cuáles son las ventajas y cuáles las limitantes en el manejo de herramientas digitales durante el proceso de diseño?

- ¿Se verifica que las herramientas del mundo digital motivan, favorecen y potencian el desarrollo del Proceso de Diseño Arquitectónico, optimizando la interacción entre docentes y alumnos en el Taller de Arquitectura?

\section{A nivel de sexto año}

Se busca profundizar en la verificación de los siguientes conceptos:

- Capacidad de comunicación gráfica de los diferentes temas-problemas abordados en el Trabajo Final de Carrera (en sus diferentes escalas: urbana regional, urbana localizada, equipamientos, tecnológicas, etc.). - Capacidad creativa y de síntesis en la representación de las ideas.

- Capacidad para producir toda la documentación técnica necesaria para la materialización del proyecto arquitectónico: el estudiante -futuro profesional- debe profundizar conocimientos y capacidades, habilidades y destrezas que le permitan, con nuevas tecnologías y recursos apropiados, elaborar de manera eficiente la documentación técnica integral de un proyecto arquitectónico.

El diagnóstico está basado en observaciones, entrevistas y análisis de documentación sobre el manejo de croquis, representaciones de plantas, cortes y vistas, así como de perspectivas polares, axonometrías y maquetas, realizados con medios analógicos y digitales, en dos y tres dimensiones. Para el análisis de la información se realizan cuadros y mapas semánticos para ordenar, sistematizar e interpretar la información, resumirla de manera cuidadosa, analizar los resultados y extraer generalizaciones significativas. Los resultados buscan determinar no solo las interrelaciones de los conocimientos entre las asignaturas, sino el estado en que se encuentran los alumnos en cada instancia de evaluación, así como los cambios que experimentan las variables en el transcurso del tiempo. Se están utilizando como insumo para realizar una propuesta de innovaciones a nivel curricular, que será compartida con los diferentes actores que intervienen en el proceso de formación de los estudiantes de Arquitectura, además de ser un documento base para la reflexión sobre nuestras propias prácticas.

\section{CÁTEDRA ARQUITECTURA IV-UPC}

En el Taller de Arquitectura se desarrolla un proceso pedagógico en el cual alumnos y docentes desafían en conjunto temas-problemas específicos del hacer proyectual. Es así que se convierte en la actividad troncal del currículum de la carrera. Se trata de que las ideas surjan de contemplar las necesidades y las técnicas de materialización, y para ello en Arquitectura IV se establecen fases o etapas del proceso proyectual que permiten a los alumnos avanzar conscientemente, desde la elaboración crítica de la alternativa de pre-partidos posibles, hasta el partido y su verificación en el anteproyecto. Los docentes aportan como tutores guías, y desarrollan un rol como tutores virtuales y coordinadores de las actividades dentro de la experiencia Taller Virtual Red Norte Grande (que combina la modalidad de educación a distancia con la presencial), lo que distingue con valor diferencial la propuesta pedagógica de la cátedra Arquitectura IV.

Los docentes desarrollan sus actividades dentro de esta experiencia innovadora vinculando y articulando el proyecto de docencia con el de investigación en curso, íntimamente relacionados, a fin de retroalimentar la actividad del taller aportando desde la investigación a la práctica docente en él. Esta experiencia se sus- 
tenta en la certeza de que, mediante la constitución de redes, las instituciones de educación superior podrán unir y compartir el potencial científico y cultural que poseen.

Hay que destacar que el Taller Virtual Red Norte Grande aborda con énfasis la necesidad de establecer vínculos, articulaciones y redes de cara a los procesos de integración regional, de modo de instalar el intercambio de experiencias, el desarrollo de prácticas conjuntas y el uso de las nuevas tecnologías (en este caso, en el proceso enseñanza-aprendizaje de la arquitectura), tal como se alienta en los lineamientos de ARQUISUR (Asociación de Escuelas y Facultades Públicas de Arquitectura del Mercosur). En este contexto los docentes de la cátedra Arquitectura IV han avanzado en una investigación descriptiva-explicativa sobre las maneras en que los alumnos de Arquitectura de la FAU-UNNE representan las imágenes arquitectónicas con métodos analógicos y digitales en la actualidad. Para ello, se realizó una evaluación diagnóstica de lo trabajado en 2013, a fin de contribuir a la producción de nuevas estrategias pedagógicas en el proceso de formación y ajustar la planificación de las cátedras y áreas involucradas.

Los principales propósitos que guiaron la investigación son los siguientes:

- Identificar y conocer las distintas maneras en que los alumnos prefiguran y construyen sus imágenes arquitectónicas.

- Verificar y sistematizar los modos y las herramientas con que los alumnos configuran las imágenes arquitectónicas, a través de un seguimiento pormenorizado de grupos de alumnos en el nivel de Taller de $4 .^{\circ}$ año de la carrera de Arquitectura.

- Analizar el impacto del mundo digital en la construcción de las representaciones gráficas de los alumnos, fundamentalmente en cada etapa del proceso proyectual.

Cabe a aclarar que en el ciclo TVRNG 2013, se trabajó en la ciudad de Concepción (Corrientes) y en los Esteros del Iberá, para la realización del trabajo denominado Puesta en Valor del Portal de Acceso Oeste a los Esteros del Iberá, provincia de Corrientes/Arquitectura para el turismo y el desarrollo sustentable. Participaron en esta experiencia virtual-académica las cátedras de Arquitectura IV UPC de la Facultad de Arquitectura y Urbanismo de la UNNE y la cátedra Arquitectura IV / Combes de la Facultad de Arquitectura y Urbanismo de la Universidad Nacional de Tucumán. Los trabajos se desarrollaron con grupos en cuatro comisiones, cuyos resultados se detallan a continuación.

\section{COMISIÓN ARQUITECTO JOSÉ ITURRIAGA}

- ¿Cuál es el impacto del mundo digital en la enseñanza-aprendizaje del proceso de diseño arquitectónico? Buscamos que los alumnos de cuarto año comprendan el concepto de que la Arquitectura no puede estar disociada del dibujo, porque los dibujos no son solo resultados finales, sino parte esencial del pensamiento del diseño. Eso lo verificamos en las diferentes etapas del proceso de diseño, y en los trabajos prácticos desarrollados pudimos observar que utilizan un porcentaje mínimo de programas digitales de todo el amplio espectro disponible actualmente. Se manejan con dos programas, y solo los utilizan para el pasado en limpio de las propuestas. Verificamos problemas en la comunicación de ideas por utilizar los programas con conocimientos muy superficiales y sin la búsqueda interesada de otros que puedan mejorar la presentación y la interacción en las etapas creativas.

- Fundamentalmente, ¿cómo influye en la representación de las ideas arquitectónicas en cada etapa?

En la mayoría de los casos analizados se pueden diferenciar claramente dos grupos: los que utilizan el concepto integral del trabajo considerando desde el inicio al medio digital como apoyo y los que traba- 
jan de manera intuitiva sin apoyo de lo digital. Los primeros encuentran en la representación digital un medio que les ayuda a repensar sus propuestas, validar conceptos, corregir y a la vez ir trabajando desde el inicio con un soporte que les facilita el arte final de la presentación del trabajo. Los segundos tienen la sensibilidad de continuar con el dibujo a mano para la transmisión de ideas como boceto referencial, a manera de diario visual en donde se registran los avances; pero esas ideas se podrían mejorar, clarificar, para pasarlas después a programas que ayuden a su comprensión.

Queda claro que el medio digital debe estar presente desde el inicio pero con diferentes grados de participación de acuerdo con la etapa del proceso en la que se encuentre. Es innegable que el dibujo definitivo, el más desarrollado, es producido casi exclusivamente por medio de programas digitales; sin embargo, en las etapas anteriores el uso de lo digital es más fragmentado y selectivo.

- La oportunidad de trabajar en una experiencia tal como El Taller Virtual, ¿favorece y optimiza la manera de representar las propuestas arquitectónicas? Siempre es un incentivo animarse a trabajar en una experiencia en la cual el alumno está obligado a comunicarse con otro a distancia, con quien puede intercambiar opiniones, información, puntos de vista, etc., y a la vez aprender juntos nuevas maneras de encarar un trabajo con objetivos comunes. Verificamos que esta experiencia de taller virtual acorta distancias que a primera vista parecían insalvables; se comparan resultados, modos y metodologías diferentes. Todo esto se traduce en un crecimiento del alumno en diferentes aspectos, desde la generación de ideas, pasando por la metodología de trabajo y el arte final presentado en formato digital, con las condicionantes necesarias que esto implica. Al encarar un trabajo virtual el alumno necesariamente debe aprender nuevos programas que le permitan encarar satisfactoriamente la experiencia.
- ¿El trabajo en red y colaborativo mejora la manera en que los alumnos expresan sus ideas en cada etapa del diseño? El trabajo en red y colaborativo lleva implícita la necesidad de expresar claramente lo que se quiere comunicar, y para eso el alumno debe manejar todos los programas que faciliten esa comunicación de ideas. La comunicación tiene que ser eficaz, rápida, clara, y buscar una respuesta que permita modificar el trabajo con la participación del grupo. Este trabajo en red se encontró con la dificultad de la agilidad en las devoluciones o respuestas, y en ese sentido no tiene tanta gravitación el programa digital como el nuevo hábito que deben tener los alumnos para trabajar con un soporte en red. Los programas digitales incorporan nuevas maneras de trabajar, con metodologías y tiempos diferentes que deben ser ejercitados para que sirvan a los efectos del trabajo encarado.

- ¿Cuáles son las ventajas y cuáles las limitantes en el manejo de herramientas digitales durante el proceso de diseño? Durante el proceso de diseño es válida la utilización de todos los medios posibles para transmitir ideas, propuestas e imágenes, pero la validez de la utilización de unas herramientas u otras depende del alumno, que decide utilizar determinadas herramientas, y no en el programa en sí mismo. De todas maneras, al ver los resultados de los trabajos de los alumnos pudimos verificar que las herramientas digitales, bien manejadas, presentan muchas ventajas; pero también al ser utilizadas por alumnos que no tienen claro el concepto y la etapa del proceso de diseño en la que se encuentran, y además poseen conocimientos superficiales de los programas utilizados, se vuelven en contra del proceso creativo, porque son manejadas incorrectamente y limitan gravemente al alumno. Por lo tanto, pierden posibilidades de la experimentación que facilita y enriquece el trabajo.

- ¿Se verifica que las herramientas del mundo digital motivan, favorecen y potencian el desarrollo del Proceso de Diseño Arquitectónico, optimizando la interacción entre docentes y alumnos en el Taller de 

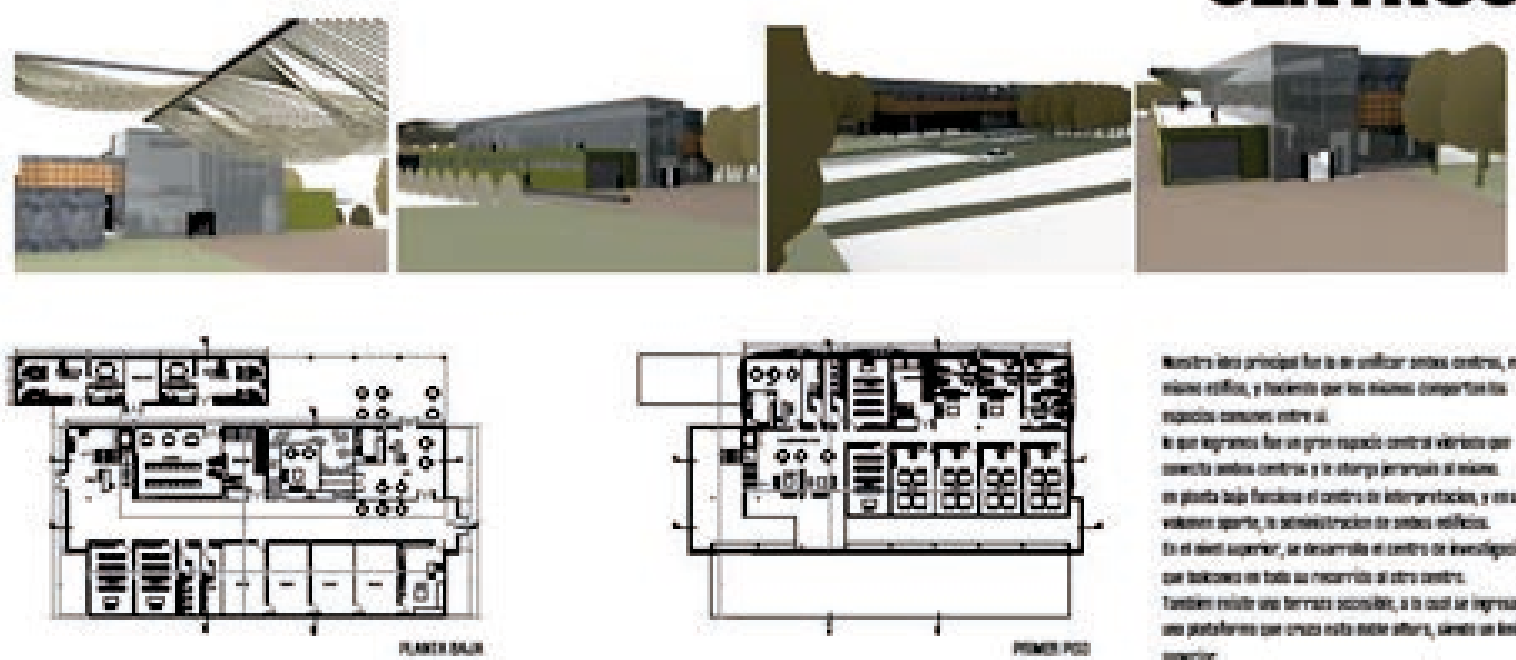

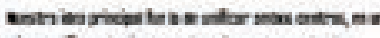

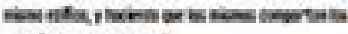

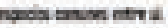

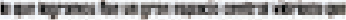

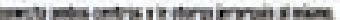

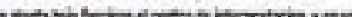

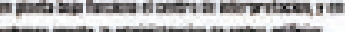

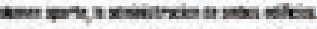

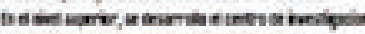

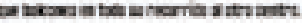

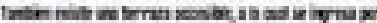

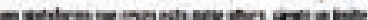
(2)

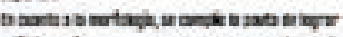

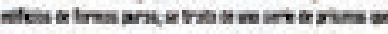
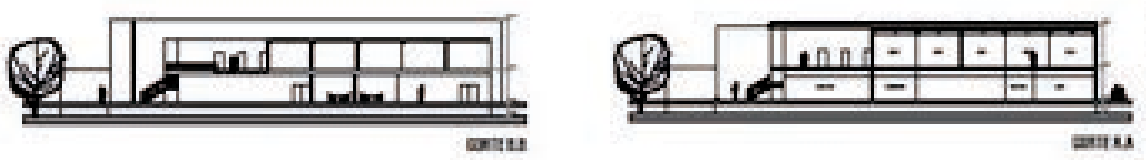

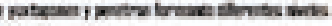
tares

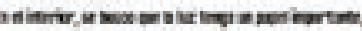

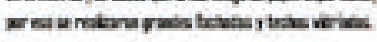
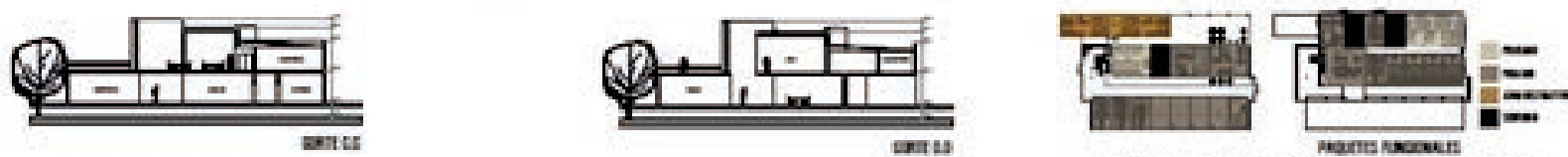

BAHEALAI. IATZ.MU

Arquitectura? Durante el desarrollo del trabajo del Taller Red Norte Grande se pudo verificar que las herramientas digitales utilizadas con inteligencia y con fines claros representan un medio de un alto valor dentro del proceso de diseño, tanto para la generación de ideas como para su comunicación.

\section{COMISIÓN ARQUITECTO SERGIO VARGAS}

Teniendo en cuenta las distintas etapas del proceso de diseño, se observan diferentes estrategias metodológicas adoptadas por los alumnos. Las modalidades de trabajo varían según los conocimientos que tengan de los distintos programas de diseño, como también el uso de la mano alzada, de acuerdo con la etapa proyectual. Se procedió al seguimiento y monitoreo, para verificar los distintos niveles encontrados en el curso.

Dentro de un proceso proyectual encontramos diferentes etapas; en la primera se observa un trabajo más flexible, en el cual la representación de las ideas arquitectónicas es realizada básicamente a mano alzada. El croquis, los ideogramas y esquemas son luego trabajados mediante programas digitales, como CorelDraw o PhotoShop. Los escanean y los trabajan para la presentación a la cátedra. En los trabajos seleccio- nados, se puede verificar cómo los alumnos utilizan y representan esta primera etapa del proceso. Para las próximas etapas del proceso de diseño, comienzan a usar otros programas digitales, como Autocad y Sketchup como herramientas, que en un principio les sirven para verificar la idea arquitectónica realizada primero a mano alzada. Estos programas son empleados hasta que tienen una mejor y mayor definición de sus proyectos; luego comienzan a experimentar con los renders, usando V-Ray como programa y metodología para mostrar los distintos renders e imágenes de su objeto arquitectónico. Algunos realizan incluso algún video del proyecto para tener una mejor interpretación. Estas herramientas de maquetas electrónicas les son muy útiles, a los efectos de verificar, y pueden comenzar a ver el espacio arquitectónico, la volumetría, los elementos de composición. Cuando manejan solo el Autocad como herramienta digital, básicamente lo ven en dos dimensiones, y les resulta muy difícil definir el espacio arquitectónico. Recién con el Sketchup lo logran, y es entonces cuando el proyecto en muchos casos entra en crisis al descubrir que su idea no es lo que estaban pretendiendo inicialmente.

Con la utilización de los distintos programas y herramientas digitales, se perciben distintas ventajas ya que los ayudan en primer término a interpretar mejor su ideas, y luego poder mostrarlas, porque la poca experiencia que tienen en el uso de la mano alzada los 
Ileva a valerse de las distintas herramientas digitales de manera temprana dentro del proceso proyectual, en el que, en un principio, resulta más adecuada la mano alzada, para lograr una visión más global del tema-problema. Luego es conveniente emplear las distintas herramientas digitales para verificar la idea y lograr una mejor visión e interpretación de los proyectos, comprobando el espacio, la volumetría, materialización, luces y sombras, etc.

Dentro del ejercicio del TVRNG, es muy valiosa la experiencia para los alumnos, como también para los docentes que participamos de ella. Creemos que no solo favorece, sino que además optimiza el poder trabajar con herramientas digitales, ya que realizar el intercambio en red y ver cómo se trabaja en otra facultad de arquitectura los obliga a investigar el uso de nuevas herramientas y programas digitales y la manera de mostrar sus proyectos para luego volcarlos al blog. La utilización de un blog para la experiencia del taller virtual también resulta muy valiosa, ya que es la manera de poder ver, compartir, comparar y relacionarse con otros compañeros.

\section{COMISIÓN ARQUITECTA GLADIS PINTOS}

Los alumnos desarrollan un proceso de diseño a partir de un tema-problema planteado con utilización de diferentes herramientas digitales según las etapas en las cuales deban expresar sus ideas. En general, se los verifica más astutos y flexibles cuando deben profundizar la representación en etapas tales como partido y anteproyecto.

Sin embargo, resulta indudable la necesidad de avanzar con la "mano alzada" en las primeras etapas de creatividad, lo que los lleva a "escanear" lo producido, transformarlo en imágenes con ayuda de CorelDraw o el PhotoShop y armarlo en una presentación tipo PowerPoint.
Al analizar la producción de los alumnos según variables tales como conocimientos conceptuales, grado de síntesis, capacidad de comprender y comunicar a través de la gráfica, se observa que los alumnos adquieren mayor solvencia en etapas del proceso de diseño que implican una mayor definición del objeto arquitectónico, en las cuales programas como Autocad y Sketchup los auxilian como soporte digital. Las ventajas con el uso de la computadora resultan notorias para clarificar la propuesta. El manejo de herramientas digitales para expresar ideas durante el proceso de diseño adquiere distintos grados de solvencia por parte de los alumnos, y resulta innegable que los programas digitales solo los ayudan en la representación de las ideas, pero aún no son un soporte en las primeras instancias de creatividad. Cuando el objeto arquitectónico adquiere mayor desarrollo, precisión y expresividad, los alumnos avanzan con Renders, que les facilita verificar sus ideas en el espacio, y es en estas etapas cuando rápidamente pueden corregir aspectos negativos del proyecto y profundizar en cuestiones constructivas-formales-espaciales.

El manejo de las proporciones y destreza para la representación en sus diferentes variantes mejora muchísimo en los alumnos con el uso adecuado de programas digitales, y les otorga incluso mayor seguridad a la hora de explicar sus ideas.

El TVRNG, como taller en red, se expresa como un taller colaborativo que propicia un ambiente de discusión e intercambio sumamente favorable e incentivador para los alumnos. El hecho de tener que manifestar sus producciones en un blog y recibir opiniones de alumnos y docentes de otras facultades los motiva a mejorar continuamente. Asimismo, el desafío que implica el taller en red para los docentes obliga a la reflexión y superación constantes.

Resulta indudable que el impacto del mundo digital en la enseñanza-aprendizaje del proceso de diseño arquitectónico es intenso y revolucionario. Aporta mu- 
etapa

prepartido arquitectónico/ideogramas
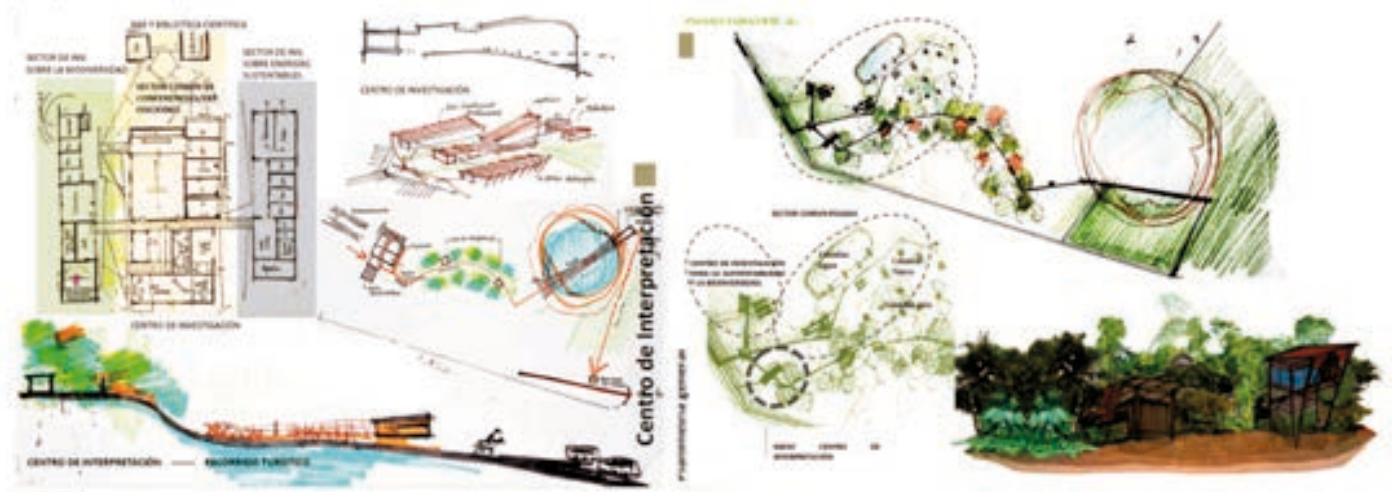

etapa B
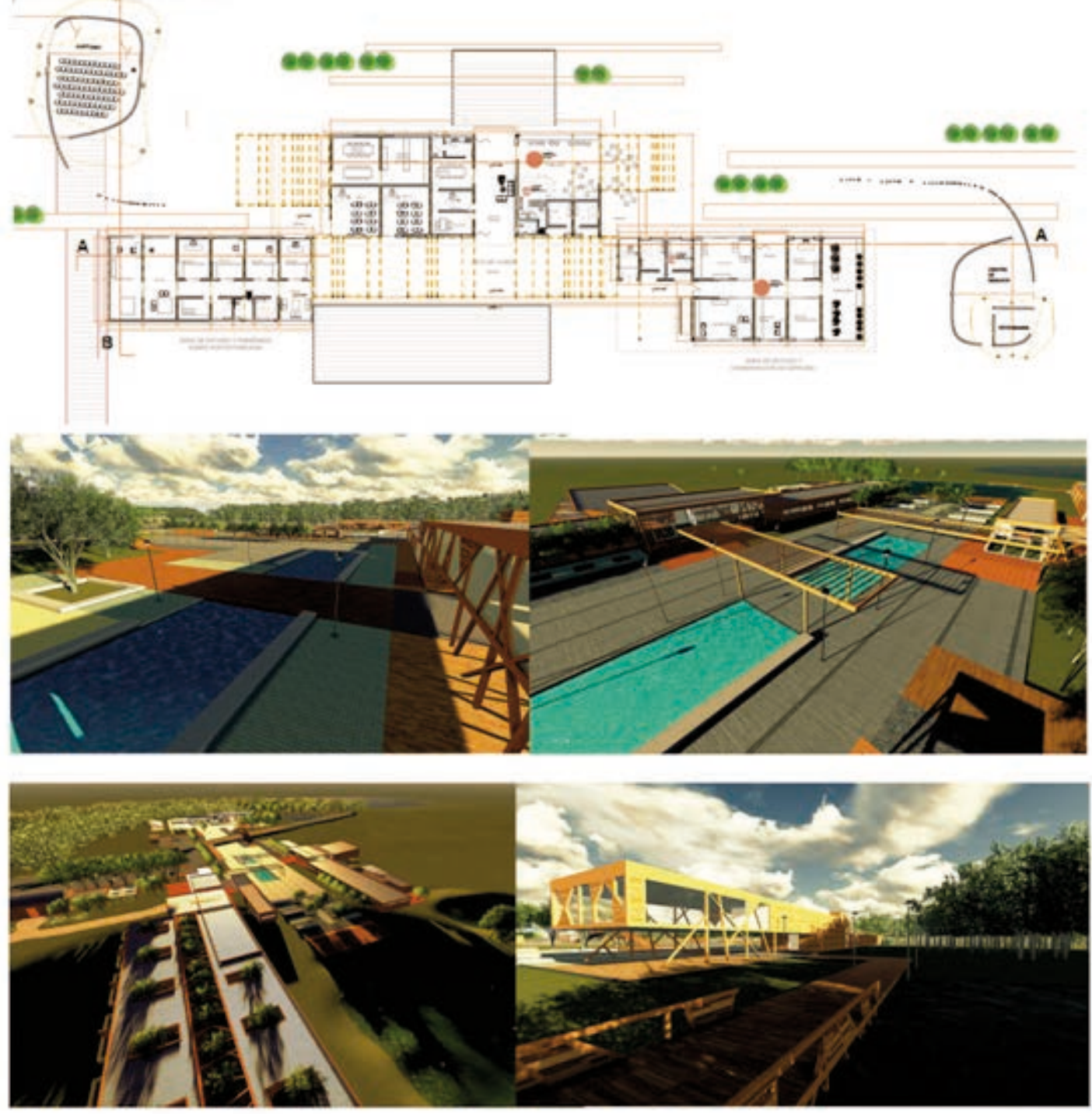


\section{anteproyecto}

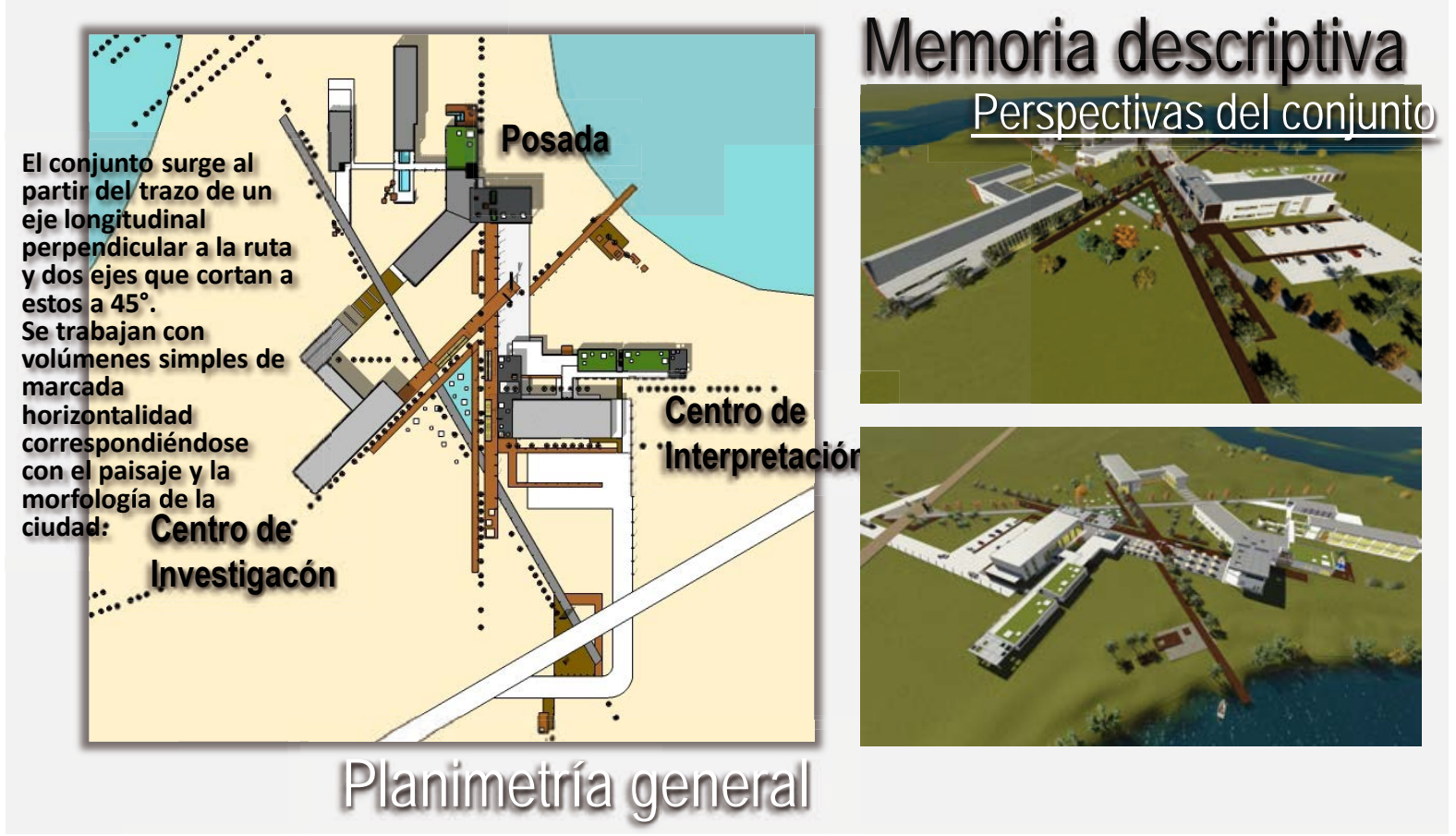

chas ventajas no solo en cuanto a la representación arquitectónica, sino además en acercar el manejo de la información y el trabajo en red, lo cual incide beneficiosamente en el alumno en todo el proceso de diseño arquitectónico. Hemos verificado - hasta ahoraen la producción de los alumnos que las herramientas del mundo digital motivan, favorecen y potencian el desarrollo del Proceso de Diseño Arquitectónico y a la vez se optimiza la interacción entre docentes y alumnos del Taller de Arquitectura.

\section{COMISIÓN ARQUITECTO GUSTAVO TRIPALDI}

- ¿Cuál es el impacto del mundo digital en la enseñanza-aprendizaje del proceso de diseño arquitectónico?

El impacto de las tecnologías digitales en este campo es multidimensional, pero a los efectos de la investigación en curso y en función de lo datos relevados y observados, se puede sintetizar en tres aspectos: a) mayor diversidad de modos de representación; b) intensificación del uso de información global en el proceso proyectual y c) disminución del uso de ideogramas conceptuales para representar las ideas y propuestas.

- Fundamentalmente, ¿cómo influye en la representación de las ideas arquitectónicas en cada etapa?

El uso de las tecnologías digitales influye con características específicas, que se detallan para cada etapa.

\section{ETAPA ANÁLISIS DE SITIO/ MODELOS ARQUITECTÓNICOS / PROGRAMA}

Se verifica un uso intensivo de información adquirida fundamentalmente en Internet, además de una gran diversidad de fuentes de información empleadas simultáneamente y una tendencia al uso excesivo de imágenes sin profundidad de análisis. Predomina el enfoque descriptivo. Se verifica una escasa producción crítica de los aspectos analizados.

\section{ETAPA DE ALTERNATIVAS}

Se comprueba una mayor libertad y la tendencia al uso de geometrías complejas, así como a representar rápidamente en maquetas digitales la propuesta arquitectónica sin desarrollar previamente y con sustento una "concepción arquitectónica" que sirva como idea rectora integral.

\section{ETAPA DE PARTIDO ARQUITECTÓNICO Y ANTEPROYECTO}

En esta etapa la influencia se verifica en que los alumnos presentan un proceso de mejora continua, dado que los medios digitales de representación les permiten corregir rápidamente los aspectos negativos de su propuesta, y pueden resolver cuestiones formales/espaciales/constructivas con mucha mayor rapidez que cuando lo hacían exclusivamente a través de técnicas manuales. 


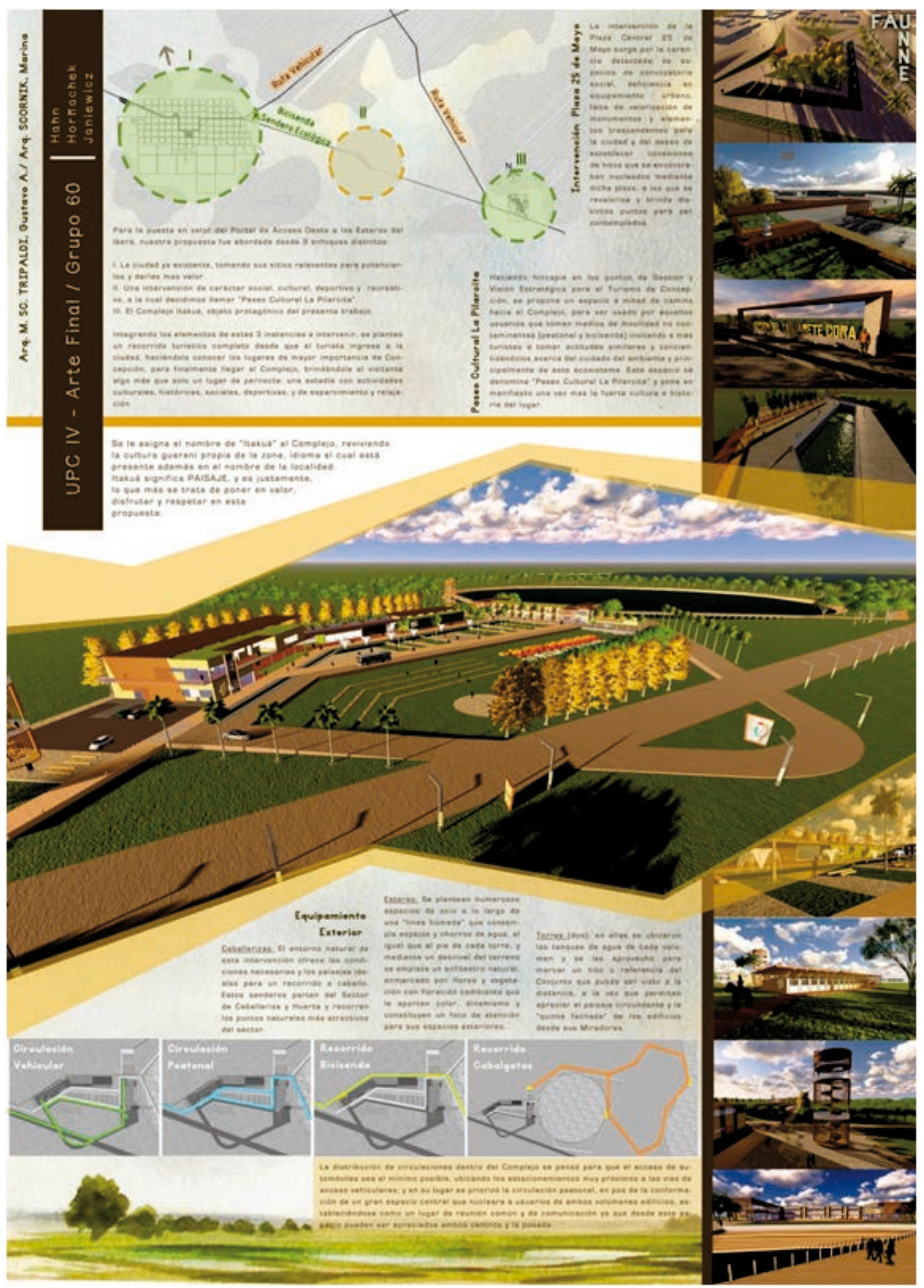


- ¿La oportunidad de trabajar en una experiencia tal como El Taller Virtual, favorece y optimiza la manera de representar las propuestas arquitectónicas?

Sí, especialmente por la interacción y la cooperación de los grupos virtuales.

- ¿El trabajo en red y colaborativo mejora la manera en que los alumnos expresan sus ideas en cada etapa del diseño?

Fundamentalmente favorece y estimula la superación constante por parte de los grupos de alumnos, dado que al encontrarse y ser visibles con su producción en la red, surge una natural voluntad de representar sus propuestas con la mejor calidad posible.

- ¿Se verifica que las herramientas del mundo digital motivan, favorecen y potencian el desarrollo del Proceso de Diseño Arquitectónico, optimizando la interacción entre docentes y alumnos en el Taller de Arquitectura?

Definitivamente, se puede responder afirmativamente: la mayor interacción facilitada por las tecnologías digitales favorece y genera nuevas sendas de exploración en la enseñanza-aprendizaje en el Taller de Arquitectura.

\section{REFLEXIONES FINALES}

Actualmente, se están produciendo profundos cambios en nuestra sociedad, que nos ubican frente a una época de transformaciones vertiginosas, que a la vez nos conducen a un nuevo tipo de sociedad y a un nuevo sistema educativo basado en estructuras y valores diferentes. Hasta la fecha, en la investigación, se obtuvieron resultados preliminares que muestran las primeras señales de confirmación de la hipótesis planteada y nos permiten asegurar que debemos tomar conciencia sobre la urgencia de revisar el modelo de enseñanza utilizado en la actualidad en nuestras asignaturas, de modo tal de aprovechar las ventajas que nos brindan las nuevas tecnologías, y aportar soluciones a los principales problemas que plantea la educación: la calidad, la inclusión, la deserción, el vínculo de la escuela media con la universidad y la capacitación docente.

El análisis de la información nos permite expresar que la formación en gráfica arquitectónica es un proceso complejo en el que intervienen diversos factores. Los principales fueron clasificados en las siguientes categorías:

1. La formación previa que acompaña al estudiante de arquitectura en el inicio de la carrera.

2. Las variables de apoyo al estudiante (situación económica, actividad laboral paralela a su formación como estudiante, tiempo que le insume el avance en la carrera según sus habilidades y destrezas).

3. La calidad de la formación según los docentes y compañeros que lo acompañen en el proceso.

4. El conocimiento de herramientas digitales fuera de la institución.

5. La singularidad del educando.

A partir del momento en que los proyectos son desarrollados con apoyo digital, aparece un universo de nuevas posibilidades formales. Los cambios que ocurren actualmente con esta amplia gama de herramientas y experimentos se reflejan no solo en la representación, sino en las formas de diseño y producción. Es ahora cuando podemos atender a lo novedoso de las formas generadas y asistir a la reorganización de los procesos de trabajo en los talleres y ver, también, cómo la incorporación de estas nuevas tecnologías ha mantenido como uno de los ejes centrales de su operar la posibilidad de dialogar con los procesos más tradicionales.

Por otro lado, la utilización de estrategias pedagógicas que reconozcan el perfil de los educandos como personas con conocimientos y sentimientos propios nos permitirá detectar diferentes ritmos y estilos de aprendizaje. Los resultados preliminares nos asombran, enriquecen y estimulan a continuar con gran motivación las actividades planeadas a desarrollar en la próxima etapa de investigación. 


\section{BIBLIOGRAFIA}

AMAYA, Blanca Lilia y BUITRAGO JEREZ, Orfa -"Educación personalizada, una modalidad educativa" Revista N² 26-www.utp.edu. co/ chumanas/revistas/revistas/rev26/buitrago.htm. Rec. el 5/ 7/ 2014.

DELGADO YANES, Magalí y REDONDO DOMíNGUEZ, Ernest (2007) Dibujo a mano alzada para arquitectos. Parramón, Barcelona. STENHOUSE, Lawrence (2004) La investigación como base de la enseñanza. Morata, Madrid.

MONTAGU, A. GROISMAN, M. PIMENTEL, D. (2004) Cultura Digital. Comunicación y Sociedad. Ed. Paidós, Buenos Aires.

PISCITELLI, Alejandro (2005) Internet la imprenta del S. XXI. Ed. Gedisa SA, Barcelona.

CAMPOS, Carlos (2012). Colección Nuevos Territorios en la Enseñanza de la Arquitectura. Ed. Nobuko.

Facultad de Arquitectura, Urbanismo y Diseño. Univ. Nac. de Córdoba. Julio 2008 "Antes de la Idea" - "Fábrica de Arquitectos".

FERNÁNDEZ, Roberto. Univ. De La República - Montevideo, Uruguay. "El Proyecto Final"

CAMPOS BAEZA, Alberto. Aprendiendo a pensar. Ed. Nobuko

CORONA MARTíNEZ, Alfonso. Ensayo sobre el Proyecto.

WRIGHT FRANK, Lloyd -CEPA- El Proceso Proyectual.

LYNCH, Kevin Planificación del Sitio.

BLOOMER, K. y MOORE, Ch. Cuerpo, Memoria y Arquitectura.

MARTÍNEZ MINDEGUÍA Francisco - Qué investigación- http://mindeguia.com/congresos/3IAU_M5_13.pdf

Recuperado el 5/7/2014.

MOORE/ALLEN Dimensiones de la Arquitectura.

TOGNERI, Jorge. Polémica en la Arquitectura

SCHAPOSNIK, Viviana. Arquitectura: investigación, teoría, proyecto. Ed. Nobuko. 